\title{
ALL-FIBER AIRBORNE COHERENT DOPPLER LIDAR TO MEASURE WIND PROFILES
}

\author{
Jiqiao Liu ${ }^{* 1,2}$, Xiaopeng Zhu ${ }^{1,2}$, Weifeng Diao, ${ }^{1,2}$, Xin Zhang ${ }^{1,2}$, Yuan Liu ${ }^{1,2}$, Decang Bi ${ }^{1,2}$, Liyuan \\ Jiang ${ }^{1,2}$, Wei Shi ${ }^{1,2}$,Xiaolei Zhu ${ }^{1,2}$,Weibiao Chen ${ }^{1,2}$ \\ ${ }^{1}$ Key Laboratory of Space Laser Communication and Detection Technology, CAS, \\ ${ }^{2}$ Shanghai Institute of Optics \& Fine Mechanics, CAS, Shanghai, China,
}

*Email: x_qiao@siom.ac.cn

\begin{abstract}
An all-fiber airborne pulsed coherent Doppler lidar (CDL) prototype at $1.54 \mu \mathrm{m}$ is developed to measure wind profiles in the lower troposphere layer. The all-fiber single frequency pulsed laser is operated with pulse energy of $300 \mu \mathrm{J}$, pulse width of $400 \mathrm{~ns}$ and pulse repetition rate of $10 \mathrm{kHz}$. To the best of our knowledge, it is the highest pulse energy of all-fiber eye-safe single frequency laser that is used in airborne coherent wind lidar. The telescope optical diameter of monostatic lidar is $100 \mathrm{~mm}$. Velocity-Azimuth-Display (VAD) scanning is implemented with 20 degrees elevation angle in 8 different azimuths. Real-time signal processing board is developed to acquire and process the heterodyne mixing signal with 10000 pulses spectra accumulated every second. Wind profiles are obtained every 20 seconds. Several experiments are implemented to evaluate the performance of the lidar. We have carried out airborne wind lidar experiments successfully, and the wind profiles are compared with aerological theodolite and ground based wind lidar. Wind speed standard error of less than $0.4 \mathrm{~m} / \mathrm{s}$ is shown between airborne wind lidar and balloon aerological theodolite.
\end{abstract}

\section{INTRODUCTION}

A coherent Doppler lidar (CDL) is proved to be an effective tool for wind profiles measurement ${ }^{[1]}$, windshear $^{[2]}$ and wake vortices detection and warning $^{[3]}$ in clear air with high temporal and spatial resolution and high accuracy in lower atmosphere layer. The laser source is the most important part in a CDL system. With the development of single frequency laser technology, $10 \mu \mathrm{m} \mathrm{CO} \operatorname{laser}^{[4]}, 1 \mu \mathrm{m}$ solid laser ${ }^{[5]}, 2 \mu \mathrm{m}$ solid laser ${ }^{[6]}, 1.6 \mu \mathrm{m}$ solid $\operatorname{laser}^{[7]}$ and $1.5 \mu \mathrm{m}$ fiber laser ${ }^{[8]}$ are utilized as the lidar transmitter source successively. Over the past decade, single frequency pulsed fiber lasers are studied widely. All-fiber CDL system at $1.5 \mu \mathrm{m}$ has attracted much attentions because of its eye safety, compact size, flexible arrangement, and mature fiber components technology from telecommunication industry ${ }^{[9]}$. It is also suitable for airborne wind profile measurement because of its stable performance in harsh environment. Several companies have developed commercial all-fiber CDL systems since 2004 ${ }^{[10]}$. In this paper, an allfiber pulsed CDL prototype system for wind sensing and some experiment results are presented. In the airborne field campaign, the CDL measured wind profiles are compared with balloon aerological theodolite and ground-based wind lidar, and good agreements are shown.

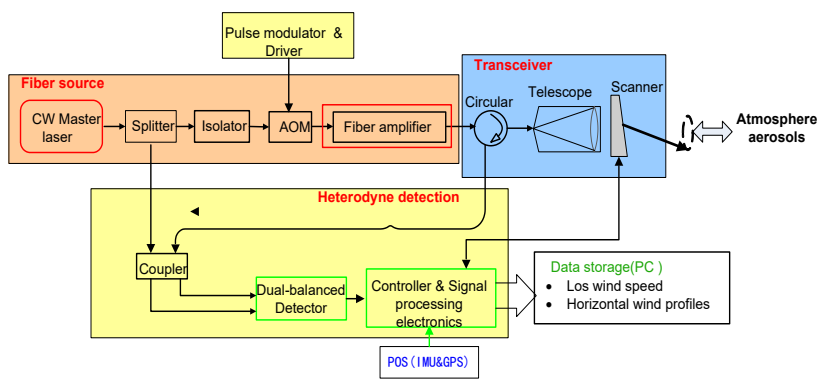

Fig.1. The block diagrams of the CDL system

\section{SYSTEM CONFIGURATION}

The block diagrams of the CDL system is shown in Fig 1. The CDL system consists of all-fiber laser source and optical transceiver and heterodyne detection unit with real-time signal processor. The CDL system is compact with size of $450 \mathrm{~mm} \times 400 \mathrm{~mm} \times 400 \mathrm{~mm}$ and mass of $50 \mathrm{~kg}$. A laptop or PC is used to control the lidar and store measured data in every azimuth angle. Further estimate of the 3-dimensions wind profiles could be implemented in the computer. 
An eye-safe, narrow-linewidth, polarized, pulsed, fiber laser based on master oscillator power amplifier (MOPA) configuration is acted as the lidar source ${ }^{[11]}$. A commercial continuous single frequency Distributed Feed Back Laser Diode (DFB-LD) with $10 \mathrm{kHz}$ linewidth and 20mw power is used as the seeder laser. The seeder is divided into two parts by the $1 \times 2$ optical coupler. One part (about $0.8 \mathrm{~mW}$ ) is sent to the balanced detectors as the local oscillator for heterodyne detection. The other part is pulsed modulated and frequency shifted by the $\mathrm{AOM}$ at repetition rate of $10 \mathrm{kHz}$, pulse duration of 400ns. The IF (Intermediate frequency - IF) frequency is $160 \mathrm{MHz}$. Through multi-stages fiber amplifiers, fiber laser with pulse energy of $300 \mu \mathrm{J}$, linewidth of $1.1 \mathrm{MHz}$ at wavelength of $1540 \mathrm{~nm}$ is obtained. The pulse shape of the output pulse is shown in Fig.2 .

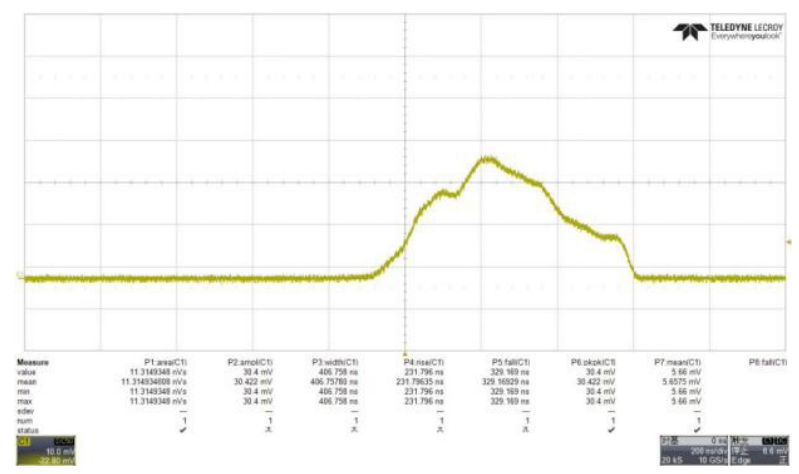

Fig.2. The shape of the output laser pulse

The optical transceiver combines a circulator and a telescope and an optical scanner. The high power circulator is used to separate transmitting fiber laser and signal backscattered by aerosols. The optical diameter of the telescope is $100 \mathrm{~mm}$. The output beam from telescope is conically scanned by a compact refractive scanner with $20^{\circ}$ deflection angle. VAD scanning could be implemented in less than 20 seconds with 8 different azimuth angles.

In the heterodyne detection unit the local oscillator from seeder is mixed with signal backscattered by aerosols from transceiver, then it is received by the InGaAs balanced detector. The heterodyne signal from the balanced receiver is sampled by the high speed AD converter with $1 \mathrm{G}$ bps rate. The sampling time is $40 \mu \mathrm{s}$ and $30 \mathrm{~m}$ range resolution is realized with $200 \mathrm{~ns}$ range gate.
Fast Fourier Transform (FFT) of 1024 points and power spectrum accumulation with 10000 pulses are implemented in every range gate. Accumulated power spectra in every azimuth are sent to the computer through RS422 interface. Then wind profiles could be calculated.The specifications of the system are summarized in the table 1.

Table1 The specifications of the CDL system

\begin{tabular}{|l|l|}
\hline Parameters & value \\
\hline Wavelength & $1540 \mathrm{~nm}$ \\
\hline Pulse energy & $300 \mu \mathrm{J}$ \\
\hline Pulse width & $400 \mathrm{~ns}$ \\
\hline Pulse repetition rate & $10 \mathrm{kHz}$ \\
\hline Power of LO & $0.8 \mathrm{~mW}$ \\
\hline Range resolution & $30 \mathrm{~m}$ \\
\hline Telescope aperture & $\Phi 100 \mathrm{~mm}$ \\
\hline Scanner & $\Phi 100 \mathrm{~mm}$ \\
& $20^{\circ}$ deflection angle \\
\hline IF & $160 \mathrm{MHz}$ \\
\hline AD & $1 \mathrm{G} / \mathrm{s}, 10 \mathrm{bit}$ \\
\hline Accumulated pulses & 10000 \\
\hline
\end{tabular}

\section{RESULTS}

\subsection{Ground experiments}

Ground validation experiments were carried out for the CDL system compared with standard radiosonde balloon. Measured wind profiles results for both instruments were shown in Fig.3 and good agreements were demonstrated. The radiosonde balloon was released at 8:00 pm on Dec 24 in Shanghai upper atmospheric sounding site $(121.46 \mathrm{E}, 31.40 \mathrm{~N})$, where was about 22 kilometers from the CDL system experiment site $(121.23 \mathrm{E}, 31.38 \mathrm{~N})$. The measured wind profiles below $0.5 \mathrm{~km}$ were ignored for comparison because of larger horizontal space between two sites. Coefficients of correlation for the CDL system and radiosonde from $0.5 \mathrm{~km}$ to $2.9 \mathrm{~km}$ were proved to be 0.93 for wind direction and 0.91 for wind speed. The standard errors of wind speed and wind direction were $0.85 \mathrm{~m} / \mathrm{s}$ and $4.0^{\circ}$, respectively. 

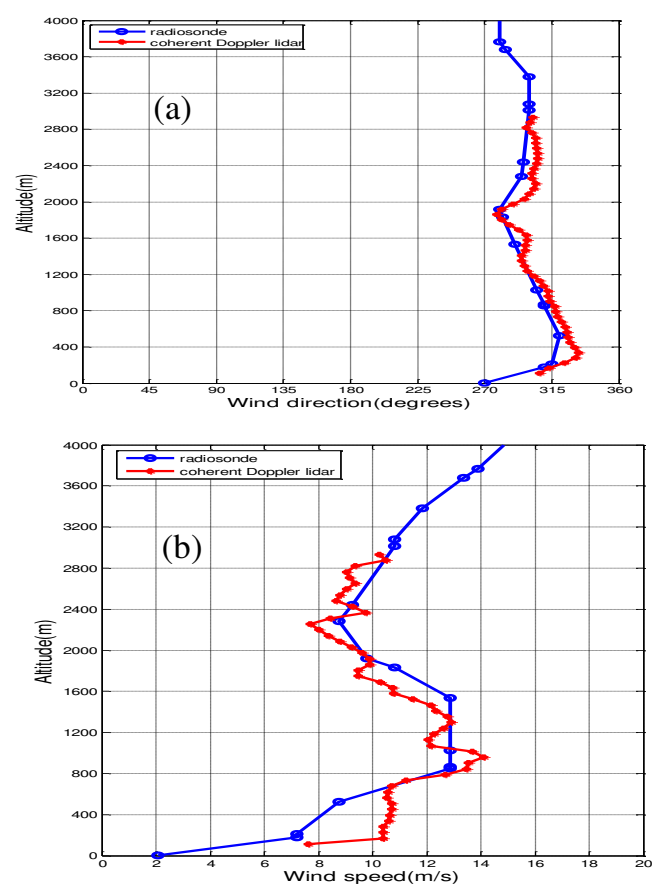

Fig.3. Comparison of wind profiles between CDL and radiosonde: (a) horizontal wind speed direction, (b) horizontal wind speed.

\subsection{Airborne experiments}

Airborne CDL validation experiment is carried in Roncheng city, Shangdong province, China on Jan 19, 2015. The CDL system is installed in a fixed wing aircraft with almost $50 \mathrm{~m} / \mathrm{s}$ speed and $2000 \mathrm{~m}$ flight height. For airborne CDL, the speed and attitude angles should be corrected to calculate accurate wind profiles. So the POS system composed of Inertial Navigation System (INS) and global positioning system(GPS) is installed in the aircraft with the lidar together to record aircraft speed and attitude angles (yaw ,pitch and roll). Wind profiles measured from airborne CDL are compared with ground-based CDL and aerological theodolite in the campaign simultaneously to assess the airborne CDL performance. The sites of the ground-based lidar and the balloon aerological theodolite are shown in Fig.4, and the distances between the aircraft ground track and the ground campaign stations are about $500 \mathrm{~m}$. The whole flight time is lasted about 5 hours, and the horizontal wind profiles with time are shown in Fig.5. Between 13:40 (Local time) and 15:40 the aircraft is completely flying above the Yellow Sea.

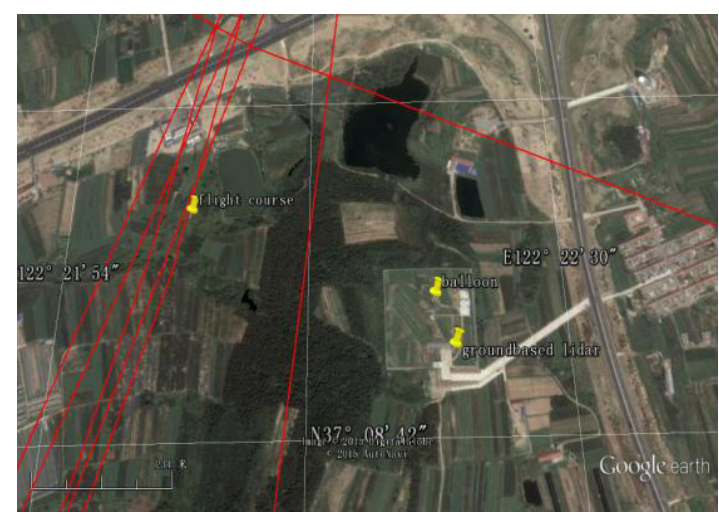

Fig.4. Aircraft ground track and ground campaign stations

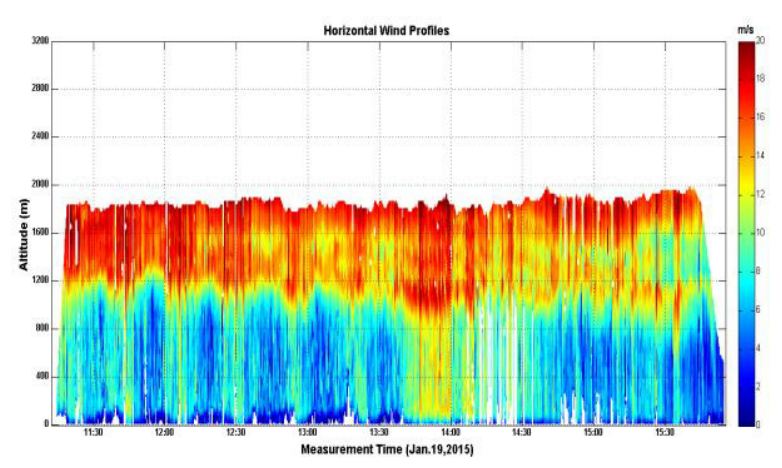

Fig.5. The horizontal wind profiles with time

For one case on 12:22 airborne lidar shows good agreements with ground-based lidar and the balloon aerological theodolite. The wind speed standard error between the three system are less $1 \mathrm{~m} / \mathrm{s}$, and the wind direction differences are about $10^{\circ}$,as shown in Fig.6 and Fig.7. Especially, wind speed standard error between airborne lidar and balloon aerological theodolite is less $0.4 \mathrm{~m} / \mathrm{s}$, with wind speed coefficient of correlation of 0.9867, which is shown in Fig.8.

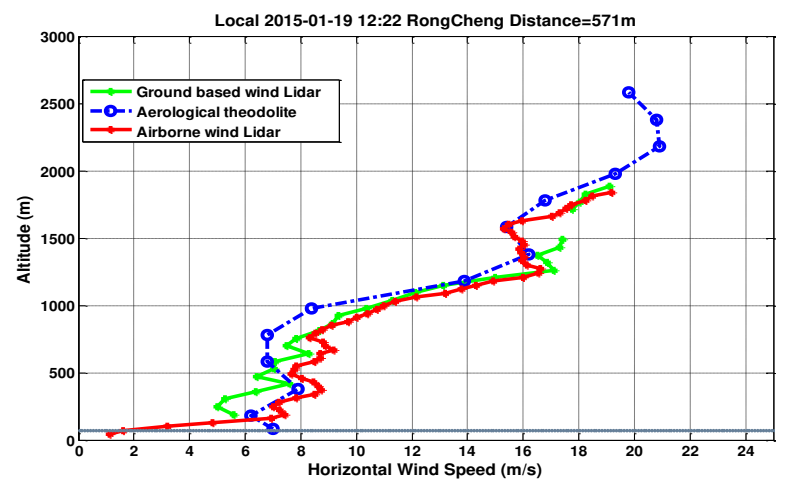

Fig.6. The wind speed profiles comparisons between the three systems. 


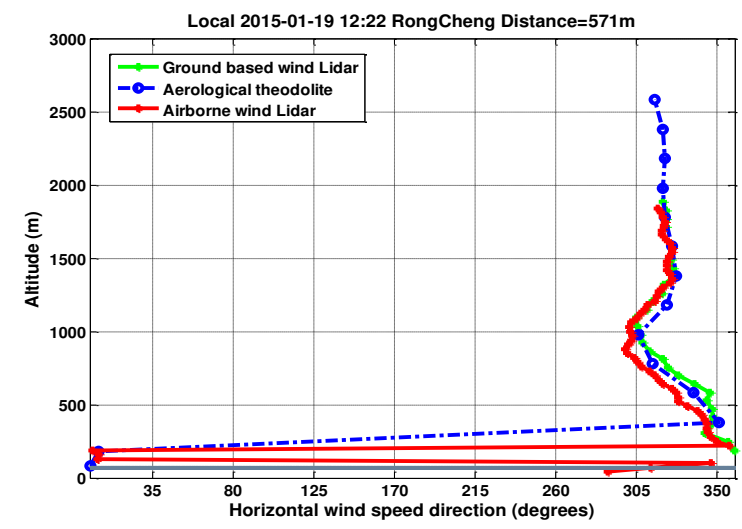

Fig.7. The wind directions profiles comparisons between the three systems.

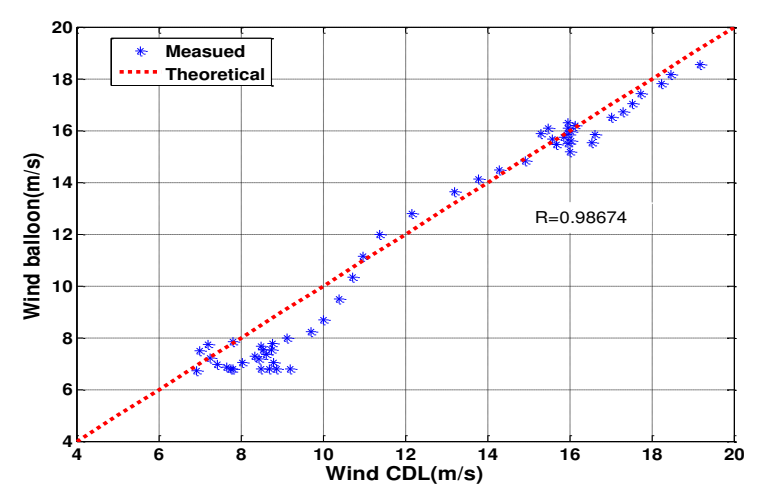

Fig.8. Linear correlation of wind speeds measured by the CDL and aerological theodolite

\section{CONCLUSIONS}

An all-fiber airborne pulsed CDL prototype with high laser pulse energy is developed to measure wind profiles. Ground and airborne campaign experiments are implemented to validate the CDL performance. In the ground campaign, the standard errors of wind speed and wind direction are shown to be $0.85 \mathrm{~m} / \mathrm{s}$ and $4.0^{\circ}$ respectively between CDL and radiosonde. In the airborne campaign, the airborne CDL measured wind profiles are compared with the ground-based CDL and the aerological theodolite. Wind speed standard error between airborne CDL and aerological theodolite are less $0.4 \mathrm{~m} / \mathrm{s}$ is validated. This lidar will be used for long-range wind profiles measurements in future in ground-based or airborne platform.

\section{ACKNOWLEDGEMENT}

This work is supported by National Natural Science Foundation of China (No. 60908036) and the Youth Innovation Found of China High Resolution Earth Observation.

\section{REFERENCES}

[1] Asaka, K., T. Yanagisawa, and Y. Hirano, 2001:1.5- $\mu \mathrm{m}$ eye-safe coherent lidar system for wind velocity measurement. SPIE. 4153: p. 321-328.

[2] Frehlich, R., 1994:Coherent Doppler lidar signal covariance including wind shear and wind turbulence. Appl. Opt. 33(27): p. 6472-6481.

[3] Dolfi-Bouteyre, A., et al., 2007:1.5 $\mu \mathrm{m}$ all fiber pulsed lidar for wake vortex monitoring, in 14th Coherent Laser Radar Conference.

[4] Huffaker, R.M. and R.M. Hardesty, 1996:Remote sensing of atmospheric wind velocities using solidstate and $\mathrm{CO} 2$ coherent laser systems. Proceedings of the IEEE. 84(2): p. 181-204.

[5] Kane, T.J., et al., 1987:Coherent laser radar at 1.06 um using Nd:YAG lasers. Opt. Lett. 12(4): p. 239-241.

[6] Jirong, Y., et al. An all solid-state 2um laser system for space coherent wind lidar. in Aerospace Conference Proceedings, 2000 IEEE. 2000.

[7] Hannon, S.M., S.R. Vetorino, and J.V. Pelk, 2007:Next generation Doppler lidar sensor at $1.6 \mu \mathrm{m}$, in 14th Coherent Laser Radar Conference: Colorado.

[8] Ando, T., et al., 2008:All-fiber Coherent Doppler LIDAR for wind sensing. Materials Research Society. 1076: p. 1076-K04-05.

[9] Kameyama, S., et al., 2007:Compact all-fiber pulsed coherent Doppler lidar system for wind sensing. Applied Optics. 46(11): p. 1953-1962.

[10] Ando, T., S. Kameyama, and Y. Hirano, 2008:Allfiber Coherent Doppler LIDAR technologies at Mitsubishi Electric Corporation, in 14th International Symposium for the Advancement of Boundary Layer Remote Sensing IOP.

[11] Zhang, X., et al., 2014:Single-frequency polarized eye-safe all-fiber laser with peak power over kilowatt. Applied Physics B. 115(1): p. 123-127. 